\title{
A Compreensão Leitora de Jovens e Adultos Tardiamente Escolarizados
}

\section{Under-Schooled Youngsters' and Adults' Reading Comprehension}

\author{
Andréa Giglio Bottino*, ${ }^{*} \&$ Jane Correa ${ }^{b}$ \\ ${ }^{a}$ Faculdade de Filosofia, Ciências e Letras de Macaé, Macaé, Brasil \\ $\&{ }^{b}$ Universidade Federal do Rio de Janeiro, Rio de Janeiro, Brasil
}

\begin{abstract}
Resumo
Foi analisada a importância de diversas habilidades linguístico-cognitivas para a compreensão leitura de jovens e adultos tardiamente escolarizados: leitura de palavras, consciência fonológica, consciência morfológica, nomeação automatizada rápida, memória de trabalho e vocabulário. A escolaridade aparece entre os melhores preditores para a compreensão leitora, incluindo as perguntas de macroestrutura, argumentação e inferência, mas não para os itens de detalhe. Além da escolaridade figuram entre os melhores preditores da compreensão leitora e das perguntas de macroestrutura a leitura de palavras e o vocabulário. $\mathrm{O}$ vocabulário é também um bom preditor para as perguntas de argumentação e juntamente com a memória de trabalho e a RAN para os itens de inferência. Finalmente, os melhores preditores para as perguntas de detalhe são memória de trabalho e RAN.

Palavras-chave: Compreensão, leitura, linguagem.
\end{abstract}

\begin{abstract}
The importance of different linguistic and cognitive abilities of reading comprehension (word reading, phonological awareness, morphological awareness, Rapid Automatized Naming (RAN), working memory and vocabulary) to under-schooled youngsters and adults was examined. Schooling is one of the best predictors for reading comprehension as well as for items related to macrostructure, argumentation and inference; but it is not to questions related to specific details. Best predictors for reading comprehension and items of macrostructure also included word reading and vocabulary. Vocabulary was also a good predictor to items related to argumentation, and along with working memory and RAN to inferential questions. Finally, best predictors to items related to specific details include working memory and RAN.

Keywords: Reading comprehension, reading, language.
\end{abstract}

A leitura está presente em atividades triviais do cotidiano. Em uma era de globalização e de rápidos avanços tecnológicos, o desenvolvimento da habilidade de compreensão leitora é um fator importante de inclusão social e de

\footnotetext{
* Endereço para correspondência: Faculdade de Filosofia, Ciências e Letras de Macaé, Rua Tenente Rui Lopes Ribeiro, 200, Centro, Macaé, RJ, Brasil, 27910-340. E-mail: agbottino@gmail.com e jncrrea@gmail.com. Agradecimentos e observações: Este texto é baseado em parte da tese defendida pela primeira autora, sob orientação da segunda autora, apresentada ao Programa de Pós-Graduação em Psicologia da Universidade Federal do Rio de Janeiro (UFRJ) em março de 2010. À Secretaria Municipal de Educação de Cabo Frio e a Escola Municipal Professor Zélio Jotha pela belíssima oportunidade de realização do trabalho de campo. Aos jovens e adultos que participaram da pesquisa que, de forma tão grandiosa, muito nos ensinaram. À Fundação de Amparo à Pesquisa do Estado do Rio de Janeiro (FAPERJ - Cientistas do Nosso Estado) e ao Conselho Nacional de Desenvolvimento Científico e Tecnológico $(\mathrm{CNPq}$ - Bolsa de Produtividade - PQ) respectivamente pelo apoio concedido às investigações realizadas pela segunda autora ao longo dos anos, o que muito contribuiu para a realização do presente trabalho.
}

formação da cidadania (Ribeiro, 1999). A leitura é uma ferramenta fundamental para o aprendizado. A inabilidade para a compreensão de textos prejudica a realização das atividades escolares.

Tomando como referência o modelo simples de leitura (SVR - simple view of reading; Hoover \& Gough, 1990) são necessárias duas habilidades para a leitura: a precisão de leitura e a compreensão. Essas habilidades se relacionam de tal forma que são experimentadas dificuldades na leitura caso haja o comprometimento de qualquer uma delas (Perfetti, Marron, \& Foltz, 1996). A precisão de leitura diz respeito ao relacionamento entre símbolos escritos e unidades sonoras, o que envolve o processamento de aspectos fonológicos e ortográficos (Griva, \& Anastasiou, 2009). Problemas no reconhecimento das palavras acabam por prejudicar a fluência de leitura e, consequentemente, o processamento e a compreensão do texto (Vellutino, Fletcher, Snowling, \& Scanlon, 2004). A imprecisão no reconhecimento das palavras durante o ato da leitura conduz o leitor a sentidos diversos daqueles possíveis de serem produzidos a partir do texto, uma vez 
que as palavras "lidas" divergem daquelas efetivamente escritas. A demora no reconhecimento da palavra, por sua vez, sobrecarrega demais a memória de trabalho, dificultando o processamento da informação e a integração do que já foi lido.

Tanto para crianças como para jovens e adultos tardiamente escolarizados, dificuldades no reconhecimento de palavras estão relacionadas a dificuldades no processamento fonológico, particularmente, em relação à consciência fonológica e à nomeação automatizada rápida (Corrêa, 2009; Morais, 2005). A consciência fonológica, ou seja, a identificação, a segmentação e manipulação intencional de unidades sonoras da fala, é imprescindível para o desenvolvimento da habilidade de leitura, uma vez que a recodificação fonológica torna possível a conversão das letras em seus sons correspondentes (Misra, Katzir, Wolf, \& Poldrack, 2004). Leitores menos habilidosos apresentam um déficit em consciência fonológica quando comparados aos bons leitores (Wagner \& Torgesen, 1987).

A Nomeação Automatizada Rápida (RAN - Rapid Automatized Naming; Denckla \& Rudel, 1974) também denominada velocidade de nomeação, recuperação lexical, recodificação fonológica de acesso ao léxico (Capellini, Ferreira, Salgado, \& Ciasca, 2007) está diretamente relacionada à fluência de leitura (Misra et al., 2004). Quanto melhor for a habilidade do leitor em reconhecer palavras escritas de forma ágil e precisa, mais serão os recursos cognitivos disponíveis para a tarefa de compreensão leitora (Cardoso-Martins \& Pennington, 2001).

A habilidade de reflexão sobre os morfemas está associada à leitura de palavras. Adultos alfabetizados apresentam melhor desempenho em tarefas de análise morfológica do que adultos não-alfabetizados (Mota \& Castro, 2007). A sensibilidade à estrutura morfológica dos vocábulos facilitaria a leitura das palavras no texto como a compreensão de seu significado pelo conhecimento dos morfemas constituintes das palavras. A consciência morfológica, ou seja, a manipulação intencional da estrutura morfológica da língua, contribuiria também para o desenvolvimento do vocabulário pela derivação de novas palavras a partir daquelas já conhecidas, favorecendo, assim, a compreensão leitora.

Na compreensão leitora existe a necessidade de se criar um modelo mental do texto que está sendo lido. O leitor gera várias informações entre as frases e as ideias contidas no texto a fim de construir uma representação integrada do que foi lido (Cain \& Oakhill, 2003). As informações devem ser mantidas na memória enquanto o leitor segue realizando a leitura do texto. $\mathrm{O}$ leitor, por outro lado, não precisa ter a preocupação de manter na memória de trabalho as palavras que leu com precisão, e sim as mensagens principais dos grupos de palavras, armazenando-as sob forma de proposições. As informações que ficarem na memória por um tempo maior serão melhores compreendidas. Contudo, em função dos limites da memória, será preciso que algumas informações sejam excluídas, dando espaço às novas informações (Kintsch, 1988, 1998). As proposições mais significativas ou temáticas que ajudarão o leitor a compreender melhor o texto ficarão na memória por um tempo maior do que aquelas que não são consideradas relevantes à compreensão do texto. Essas proposições são denominadas de macroproposições e a estrutura temática predominante é denominada macroestrutura. A explicação ou a justificativa que se segue para se chegar ao tema é denominado de argumentação. Por sua vez, os detalhes constituem informações adicionais e não-essenciais à compreensão do texto. Destaca-se também, no processamento do texto, a inferência, que diz respeito aos acréscimos plausíveis e importantes para a construção da coerência por meio da conexão entre as informações trazidas pelo texto e os conhecimentos prévios do leitor (Kintsch \& van Dijk, 1978).

A compreensão leitora e os diferentes níveis de processamento do texto durante a leitura estão associados à integração de múltiplas habilidades linguístico-cognitivas, muitas delas relacionadas ao reconhecimento da palavra e ao seu significado. Neste sentido, o presente estudo tem como objetivo examinar o papel de tais habilidades para o entendimento do desenvolvimento da habilidade de leitura de jovens e adultos escolarizados tardiamente, analisando o papel da precisão de leitura, do processamento fonológico (consciência fonológica, memória de trabalho e nomeação automatizada rápida), da consciência morfológica e do nível de vocabulário para a compreensão textual destes jovens e adultos.

Leitores habilidosos são proficientes no reconhecimento de palavras. Uma vez que as palavras sejam lidas com precisão, mais recursos cognitivos podem ser liberados para a compreensão leitora. Palavras desconhecidas podem ser lidas tanto melhor quanto sejam as habilidades metalinguísticas do leitor, tanto no nível fonológico como morfológico. A extensão do vocabulário e a fluência com que é acessado estão associadas à produção de sentidos na leitura. A integração das diversas proposições contidas no texto pode ser tanto melhor realizada quanto os recursos da memória de trabalho disponíveis.

Dado o conjunto de evidências empíricas acerca do desenvolvimento das habilidades de leitura, espera-se que as diversas habilidades linguístico-cognitivas examinadas estejam associadas ao desempenho dos jovens e adultos escolarizados tardiamente em compreensão leitora. Neste sentido, um dos objetivos deste trabalho é poder delimitar o conjunto destas habilidades, aquelas que seriam as melhores preditoras do desempenho dos jovens e adultos escolarizados tardiamente.

As proposições presentes no texto não são tratadas pelo leitor de forma homogênea. Desta maneira, é possível que diferentes habilidades linguístico-cognitivas estejam associadas aos diferentes níveis de processamento do texto. Este trabalho tem também como objetivo, delimitar as habilidades que seriam as melhores preditoras do desempenho de jovens e adultos tardiamente escolarizados nos diferentes níveis de processamento do texto em que foram avaliados. 


\section{Método}

\section{Participantes}

50 jovens e adultos frequentando classes noturnas de uma escola pública no Município de Cabo Frio, sendo 21 do sexo masculino e 29 do sexo feminino, com idade entre 16 e 69 anos (média de 36 anos e 04 meses). Os aprendizes cursavam os anos finais do primeiro segmento do Ensino Fundamental, sendo 18 alunos no $4^{\circ}$ ano e 32 no $5^{\circ}$ ano. Todos os jovens e adultos assinaram o termo de consentimento livre e esclarecido, participando voluntariamente da pesquisa. O projeto foi aprovado pelo Comitê de Ética em Pesquisa do Instituto Deolindo Couto sob o protocolo $\mathrm{n}^{\mathrm{o}} 001 / 09$

\section{Tarefas}

Compreensão de Texto. Segundo as recomendações metodológicas da pesquisa de caso único acerca do número mínimo de observações para avaliação do desempenho dos jovens e adultos participantes da pesquisa (Wilson, 2000) foram considerados os desempenhos dos participantes em três tarefas de compreensão de texto. Os textos apresentados aos jovens e adultos foram empregados anteriormente por Bottino (2004) e Bottino, Emmerick e Soares (2010).

Os participantes receberam cada texto digitado juntamente com as respectivas perguntas. Antes da realização da tarefa pelos aprendizes, o pesquisador fazia a leitura oral do texto para toda a turma. Cada texto era seguido de 20 perguntas dissertativas sobre seu conteúdo, sendo as perguntas classificadas da seguinte forma: 07 questões sobre macroestrutura; 06 questões sobre argumentação; 04 questões sobre inferências e 03 sobre detalhes (Bottino et al., 2010). A avaliação da pertinência das perguntas feitas sobre o conteúdo dos textos e sua classificação, segundo o modelo de van Dijk e Kintsch (1983), foi realizada por três juízes independentes. Para efeito da análise dos resultados, foram estabelecidas duas medidas de fidedignidade das tarefas de compreensão leitora. A primeira relacionada à consistência interna de cada tarefa por meio do índice de discriminação dos itens de cada texto (correlação bisserial). Posteriormente, foram calculados os coeficientes Alpha de Cronbach para cada uma das tarefas. Do texto 1 foram eliminadas 2 perguntas de argumentação devido ao seu baixo índice de discriminação, ficando então a tarefa com 18 itens. O Coeficiente Alpha da tarefa foi de 0,73 . Para o segundo texto, 4 itens não alcançaram o nível de significância esperado e desta forma eliminados. A tarefa ficou então com 16 itens, sendo o Coeficiente Alpha da tarefa de 0,80 . Finalmente, para o terceiro texto, 3 itens apresentaram baixo coeficiente de discriminação, ficando, então, a tarefa com 17 itens. O Coeficiente Alpha da tarefa foi de 0,76 .

Nomeação Automatizada Rápida. A Nomeação Automatizada Rápida foi avaliada através da tarefa proposta por Denckla e Rudel (1974), normatizada no Brasil por Ferreira, Capellini, Ciasca, e Tonelotto (2003). Foram qua- tro tarefas para realização individual envolvendo respectivamente cores (preto, verde, azul, vermelho e amarelo), dígitos $(4,6,2,7,9)$, letras (o, a, s, d, p) e figuras (chave, pente, relógio, guarda-chuva, tesoura). Para cada tarefa havia um cartaz com 05 linhas e 10 colunas. As cores, os dígitos, as letras e as figuras foram dispostas de forma aleatoria, respectivamente, em cada cartela. A instrução dada aos participantes era:

Preste atenção, vou apresentar para você vários cartazes

diferentes. Um com letras, outro com cores, outro com números e o último com gravuras. Você deverá dizer o mais rápido possível, em uma sequência, da esquerda para direita, de cima para baixo o nome das letras, das cores, dos números e das gravuras que aparecem em cada cartaz.

O tempo para a nomeação realizada em cada uma das cartelas foi cronometrado em segundos.

Memória de Trabalho. A memória de trabalho foi avaliada individualmente através de uma tarefa de sequência de dígitos de ordem direta adaptada por Nascimento (2000) do WAIS-III (Escala de Inteligência Wechsler para Adultos). A primeira sequência iniciava com dois dígitos e a última terminava com nove dígitos, existindo uma escala gradual de dificuldades. A instrução dada era a de repetir, em sequência, os números que eram falados pelo pesquisador. A primeira sequência de dois dígitos foi tomada como item de exemplo. A tarefa era suspensa quando o participante fracassava em duas tentativas de uma série.

Precisão de Leitura. A precisão de leitura foi avaliada pelo subteste de leitura do TDE - Teste de Desempenho Escolar (Stein, 1994). A tarefa constava de 70 palavras para serem lidas individualmente em voz alta. As palavras eram dispostas em uma única cartela segundo uma escala gradual de dificuldade.

Consciência Fonológica. A consciência fonológica foi avaliada individualmente através de duas tarefas de análise fonêmica: julgamento e subtração de fonema inicial. As tarefas foram desenvolvidas pelo Laboratório de Desenvolvimento Cognitivo e da Linguagem do Departamento de Psicologia da Universidade Federal de Minas Gerais (Cardoso-Martins \& Michallick-Triginelli, 2009). Na primeira tarefa era preciso que o participante identificasse, dentre três palavras representadas por meio de figuras, quais eram as duas que começavam com o mesmo som (Exemplo: baralho, serrote e buzina). As figuras eram coloridas e apresentadas em série de três em cada folha. O coeficiente de fidedignidade (Alpha de Cronbach) para tarefa de julgamento de semelhança de fonema inicial foi então de 0,86 . Para a subtração de fonema, pedia-se que o participante retirasse o som do início de uma palavra, formando assim uma nova palavra (Exemplo: 'anão' sem o /a/ fica 'não'). O coeficiente de fidedignidade (Alpha de Cronbach) para a tarefa de subtração de fonema inicial foi de 0,98 .

Consciência Morfológica. A consciência morfológica foi avaliada pela tarefa de analogia de palavras empregada 
por Correa e Dockrell (2007). A tarefa de analogia compreendeu 20 itens. Para cada item foram apresentados dois pares de palavras em cada folha ofício. O examinador lia e mostrava o primeiro par de palavras (Exemplo: cabeleireira - cabelo) e solicitava que fizesse o mesmo tipo de transformação observada neste par de palavras para que fosse enunciada a palavra que faltava para completar o segundo par de palavras (sapateiro - ?). O coeficiente de fidedignidade (Alpha de Cronbach) da tarefa de analogia morfológica foi de 0,72 .

Vocabulário. Avaliado pela tarefa de vocabulário do WAIS-III adaptada por Nascimento (2000). A tarefa consistia em 36 vocábulos. O examinador apresentava cada vocábulo oralmente e depois solicitado que cada participante dissesse o significado das palavras (Nascimento, 2000). A aplicação do teste era suspensa quando o participante obtinha seis erros consecutivos. As respostas dos examinados foram pontuadas de acordo com os seguintes critérios: zero para a resposta errada ou não falada, um ponto para as respostas corretas.

\section{Procedimentos}

As tarefas realizadas individualmente estavam relacionadas às habilidades linguístico-cognitivas: nomeação automatizada rápida, memória de trabalho, precisão de leitura, consciência fonológica, consciência morfológica e vocabulário. As tarefas de realização individual foram aplicadas, pelo pesquisador, em duas sessões de trabalho individual com cada participante. As tarefas de compreensão de texto foram aplicadas coletivamente em sala de aula. Na primeira sessão foram aplicadas as tarefas de consciência fonológica, nomeação automatizada rápida e vocabulário. Na segunda sessão, as tarefas de consciência morfológica, precisão de leitura e memória de trabalho. A ordem das tarefas foi randomizada em cada sessão para cada um dos participantes. Cada sessão teve uma duração média de 30 minutos.

\section{Resultados}

Os resultados foram expressos em proporção média entre o número de acertos e o número de itens da tarefa em função da escolaridade. Foi calculada uma medida geral de compreensão leitora por meio do desempenho dos participantes em todas as perguntas dos três textos expressa em proporção média de acertos. O desempenho dos participantes para os diferentes níveis de tratamento do texto foi calculado a partir da proporção média de acertos respectivamente às perguntas de macroestrutura, detalhe, argumentação e inferência dos três textos (Tabela 1).

Tabela 1

Proporção Média de Acertos na Medida Geral de Compreensão Leitora e nos Diferentes Níveis de Tratamento do Texto

\begin{tabular}{lcccc}
\hline \multirow{2}{*}{\multicolumn{1}{c}{ Leitura }} & \multicolumn{2}{c}{$4^{\circ}$ ano $(n=18)$} & \multicolumn{2}{c}{$5^{\circ}$ ano $(n=32)$} \\
\cline { 2 - 5 } & $M$ & $D P$ & 0,66 & 0,14 \\
\hline Compreensão & 0,52 & 0,16 & 0,51 & 0,15 \\
Macroestrutura & 0,32 & 0,2 & 0,86 & 0,20 \\
Detalhe & 0,77 & 0,23 & 0,67 & 0,18 \\
Argumentação & 0,53 & 0,12 & 0,81 & 0,16 \\
Inferência & 0,69 & 0,20 & & \\
\hline
\end{tabular}

Foi realizada uma ANOVA de delineamento misto, tendo como fatores a escolaridade e o nível de tratamento do texto segundo o tipo de pergunta apresentada (macroestrutura, inferência, argumentação e detalhe). Houve um efeito significativo da escolaridade $[F(1,48)=9,45, p=$ $0,003]$, tendo os estudantes do $5^{\circ}$. ano o melhor desempenho na resposta às diferentes questões acerca dos textos lidos. Independentemente da escolaridade o desempenho dos jovens e adultos variou significativamente em função do tipo de pergunta feita $[F(3,144)=106,63, p=\leq 0,001]$. Post-hoc testes (Bonferroni) mostraram que o desempenho dos participantes diferiu significativamente $(p<0,05)$ e em ordem crescente de acertos para as perguntas de macroestrutura, argumentação, inferência e detalhe, exceto entre os itens inferência e detalhe, para os quais não houve diferença significativa.

\section{Correlatos Linguístico-Cognitivos \\ da Compreensão Leitora}

A Tabela 2 apresenta a média dos escores obtidos pelas crianças nas diversas habilidades linguístico-cognitivas avaliadas em função da escolaridade. Os escores das habilidades de reconhecimento de palavras e de consciência fonológica foram calculados em proporção média de acertos. Os escores médios do nível de vocabulário e da memória de trabalho foram obtidos a partir dos escores padronizados para cada tarefa segundo a idade de cada participante conforme adaptação realizada por Nascimento (2000). As habilidades de nomeação automatizada rápida (RAN) foram calculadas no tempo (em segundos) para a realização da tarefa. 
Bottino, A. G. \& Correa, J. (2013). A Compreensão Leitora de Jovens e Adultos Tardiamente Escolarizados.

Tabela 2

Escores Médios para as Diversas Habilidades Linguístico-Cognitivas Segundo a Escolaridade

\begin{tabular}{lccccc}
\hline & \multicolumn{2}{c}{$4^{\circ}$ ano $(n=18)$} & \multicolumn{2}{c}{$5^{\circ}$ ano $(n=50)$} & \multicolumn{1}{c}{$t$} \\
\cline { 2 - 6 } \multicolumn{1}{c}{ Habilidades } & $M$ & $D P$ & $M$ & $D P$ & $0,77^{* *}$ \\
\hline Reconhecimento de palavras & 0,43 & 0,32 & 0,65 & 0,24 & $2,14^{*}$ \\
Analogia & 0,34 & 0,16 & 0,48 & 0,2 & $2,65^{* *}$ \\
Subtração & 0,31 & 0,37 & 0,62 & 0,41 & 0,62 \\
Julgamento & 0,69 & 0,2 & 0,72 & 0,19 & 0,99 \\
Vocabulário & 5,89 & 1,97 & 6,5 & 2,2 & $3,37^{*}$ \\
Memória de trabalho & 4,67 & 1,71 & 6,22 & 1,48 & $2,30^{*}$ \\
RAN alfanumérica & 78,61 & 30,8 & 62,09 & 20,58 & 0,95 \\
RAN figurativa & 117,44 & 43,03 & 106,22 & 38,25 & \\
\hline
\end{tabular}

$* p<0,05 ; * * p<0,01$.

Como a compreensão leitora varia de forma significativa em função da escolaridade, examinou-se a correlação entre as diversas habilidades linguístico-cognitivas e a compreensão leitora, controlada a escolaridade (Tabela $3)$. Todas as habilidades linguístico-cognitivas correlacionaram-se significativamente com a medida geral de compreensão leitora.

Tabela 3

Correlação (Pearson) entre a Compreensão Leitora, os Diversos Niveis de Tratamento do Texto e as Habilidades Linguístico-Cognitivas Avaliadas Controlada a Escolaridade

\begin{tabular}{lccccc}
\hline \multicolumn{1}{c}{ Habilidades } & Compreensão & Macroestrutura & Argumentação & Detalhe & Inferência \\
\hline RAN Alfanumérica & $-0,44^{* *}$ & $-0,35^{*}$ & $-0,34^{*}$ & $-0,54^{* *}$ & $-0,27$ \\
RAN Figurativa & $-0,37^{* *}$ & $-0,26$ & $-0,29^{*}$ & $-0,39^{* *}$ & $-0,33^{*}$ \\
Leitura & $0,47^{* *}$ & $0,46^{* *}$ & $0,31^{*}$ & $0,54^{* *}$ & 0,23 \\
Analogia & $0,29^{*}$ & 0,23 & $0,28^{*}$ & 0,27 & 0,16 \\
Julgamento & $0,28^{*}$ & 0,25 & 0,18 & 0,27 & 0,22 \\
Subtração & $0,41^{* *}$ & $0,40^{* *}$ & $0,35^{*}$ & $0,37^{* *}$ & 0,17 \\
Memória de Trabalho & $0,39^{* *}$ & $0,30^{*}$ & $0,28^{*}$ & $0,46^{* *}$ & $0,34^{*}$ \\
Vocabulário & $0,48^{* *}$ & $0,42^{* *}$ & $0,41^{* *}$ & $0,39^{* *}$ & $0,34^{*}$ \\
\hline
\end{tabular}

$* p<0,05 ; * * p<0,01$.

Foi, então, realizada uma análise de regressão múltipla com o objetivo de examinar quais das diversas habilidades linguístico-cognitivas avaliadas seriam as melhores preditoras da medida geral de compreensão leitora dos jovens e adultos entrevistados, controlada inicialmente a escolaridade. Os fatores inseridos na análise de regressão para a compreensão leitora foram: consciência morfológica, subtração de fonemas iniciais, julgamento de fonemas ini- ciais, vocabulário, memória de trabalho, leitura, nomeação automatizada rápida (tarefas figurativa e alfanumérica).

Os resultados de tal análise mostraram que os melhores preditores do desempenho em compreensão leitora dos jovens e adultos entrevistados $\left[R^{2}=0,46, F(3,46)=13\right.$, $38, p<0,01]$ foram a escolaridade $(\beta=0,26, p=0,028)$, a precisão em leitura $(\beta=0,35, p=0,007)$ e o nível de vocabulário $(\beta=0,33, p=0,007)$. 
A Tabela 3 apresenta, também, os coeficientes de correlação entre os diferentes níveis de tratamento do texto pelos jovens e adultos e as diversas habilidades linguístico-cognitivas tendo sido controlada a escolaridade. Observa-se que a macroestrutura correlacionou-se negativamente com a nomeação automatizada rápida apenas na tarefa alfanumérica e positivamente com a leitura, subtração de fonema, memória de trabalho e vocabulário. A argumentação só não se correlacionou significativamente com o julgamento de fonema inicial. Os itens de detalhe só não se correlacionaram significativamente com a tarefa de consciência morfológica. A inferência correlacionou-se significativamente com a tarefa de nomeação automatizada rápida (tarefa figurativa), memória de trabalho e vocabulário.

Foram realizadas análises de regressão múltipla com o objetivo de examinar quais das diversas habilidades linguístico-cognitivas avaliadas seriam as melhores preditoras para cada nível de tratamento do texto. Tendo a macroestrutura como variável dependente e tendo sido controlada a escolaridade, foi realizada uma análise de regressão múltipla tendo como fatores: nomeação automatizada rápida (tarefa alfanumérica), leitura, subtração de fonema, memória de trabalho e vocabulário. Os resultados de tal análise mostraram que os melhores preditores para a macroestrutura $\left[R^{2}=0,45, F(3,46)=12,34, p<0,01\right]$ foram a escolaridade $(\beta=0,30, p=0,016)$, a leitura $(\beta=0,35$, $p=0,008)$ e o vocabulário $(\beta=0,27, p=0,024)$.

Tendo a argumentação como variável dependente e tendo como controle o fator escolaridade, foi realizada uma análise de regressão múltipla tendo como fatores: nomeação automatizada rápida (tarefa alfanumérica e figural), leitura, subtração de fonema, memória de trabalho, analogia morfológica e vocabulário. Os resultados de tal análise mostraram que o melhor preditor para argumentação $\left[R^{2}=0,46, F(2,47)=9,89, p<0,01\right]$ foram a escolaridade $(\beta=0,34, p=0,009)$ e o vocabulário $(\beta=$ $0,38, p=0,003)$.

Tendo os itens de detalhe como variável dependente e controlada a escolaridade, foi realizada uma análise de regressão múltipla tendo como fatores: nomeação automatizada rápida (tarefa alfanumérica), leitura, memória de trabalho, consciência fonológica (subtração e julgamento) e vocabulário. Os resultados de tal análise mostraram que os melhores preditores para os itens de detalhe $\left[R^{2}=0,43\right.$, $F(3,46)=11,62, p<0,01]$ foram: nomeação automatizada rápida (tarefa alfanumérica) $[\beta=0,47, p<0,01]$ e memória de trabalho $(\beta=0,38, p=0,004)$.

Tendo a inferência como variável dependente, foi realizada uma análise de regressão múltipla tendo como fatores: tarefa de nomeação automatizada rápida (tarefa figurativa), memória de trabalho e vocabulário. Os resultados de tal análise mostraram que os melhores preditores para inferência $\left[R^{2}=0,28, F(3,46)=5,82, p<0,01\right]$ foram: memória de trabalho $(\beta=0,30, p=0,038)$ e nomeação automatizada rápida (tarefa figurativa; $\beta=0,27, p=0,046$ ).

\section{Discussão}

Investigou-se o desempenho de jovens e adultos tardiamente escolarizados em compreensão leitora e os correlatos linguístico-cognitivos desta habilidade. Foram, também, investigados os correlatos linguístico-cognitivos dos níveis de tratamento do texto segundo a perspectiva de van Dijk e Kintsch (1983). Do conjunto das habilidades linguístico-cognitivas avaliadas, um dos objetivos deste trabalho foi o de delimitar aquelas que seriam as melhores preditoras do desempenho dos jovens e adultos em uma medida geral de compreensão leitora. Uma vez que há diferentes níveis de tratamento do texto durante a leitura, um segundo objetivo desta investigação foi, então, o de delimitar as habilidades linguístico-cognitivas que seriam as melhores preditoras do desempenho de jovens e adultos tardiamente escolarizados nestes diferentes níveis de processamento do texto.

A escolaridade mostra-se um fator importante para o desenvolvimento da compreensão leitora. Desta forma, para a análise dos correlatos linguístico-cognitivas da compreensão leitora de jovens e adultos tardiamente escolarizados fez-se necessário que se pudesse controlar estatisticamente o efeito da escolaridade. Feito isto, correlacionaram-se significativamente com a medida geral de compreensão leitora todas as habilidades cognitivas avaliadas: processamento fonológico (consciência fonológica, nomeação automatizada rápida e memória de trabalho), processamento morfológico e vocabulário. Dentre este conjunto de habilidades, a precisão de leitura e o vocabulário apareceram como os melhores preditores dos escores dos jovens e adultos tardiamente escolarizados em compreensão textual.

Nossos resultados confirmam a importância, para a compreensão leitora, da precisão com que as palavras são reconhecidas, conforme previsto no modelo simples de leitura (Cain \& Oakhill, 2003). A precisão de leitura significa o reconhecimento ou a pronúncia das palavras correspondentes às palavras escritas (Galletly, Knight, Dekkers, \& Galletly, 2009). Com a leitura das palavras cria-se uma mensagem falada que auxilia o leitor no processo de construção da interpretação do material escrito. A habilidade de reconhecimento das palavras permite que o leitor possa ir além da superfície linguística do texto, não importando a complexidade dos padrões ortográficos encontrados. Em todas as idades, os melhores compreendedores de texto são aqueles indivíduos que têm mais facilidade para a leitura de textos mesmo que estes incluam vocábulos com padrões ortográficos mais complexos ou palavras menos frequentes do cotidiano do leitor (Stanovich, 1993).

A precisão de leitura é necessária, porém não-suficiente, para o desenvolvimento da compreensão textual. A leitura envolve a interpretação da mensagem contida no texto e a integração dessa mensagem com aquelas relacionadas ao conhecimento de mundo do leitor (Colomer \& Camps, 2002). O vocabulário e a precisão de leitura não apenas 
se somam na contribuição que fazem ao desenvolvimento da habilidade de leitura, mas interagem. Na leitura de um texto, o leitor ao se deparar com a forma escrita de uma palavra, na maioria das vezes já possui previamente o significado relacionado àquela grafia. Assim sendo, o nível de vocabulário do leitor pode auxiliar a construção do léxico ortográfico. Por outro lado, um vocabulário limitado restringe a possibilidade de o leitor utilizar o contexto para ler palavras para as quais encontra dificuldade em ler com precisão (Dockrell \& Lindsay, 2004). Uma das grandes dificuldades dos compreendedores menos habilidosos diz respeito à sua habilidade de usar o contexto como recurso que auxilie a precisão na leitura das palavras (Nation \& Snowling, 1998).

O desconhecimento de alguns ou vários vocábulos do texto, particularmente se estes forem elementos fundamentais para a construção da representação mental do texto pelo leitor, pode dificultar ou mesmo comprometer o processo de compreensão leitora (Sánchez, 2002). O vocabulário pode também mediar o desempenho da memória de trabalho (Nation, Adams, Bowyer-Crane, \& Snowling, 1999), o que auxiliaria o processamento das informações no texto e a realização de inferências. Um texto é mais facilmente lembrado quando o leitor conhece o significado das palavras.

Apesar das habilidades de consciência fonológica e consciência morfológica parecerem desempenhar um papel importante para a compreensão leitora, esta contribuição parece não ser realizada de forma direta. Apesar das correlações significativas encontradas inicialmente, as habilidades metalinguísticas não aparecem como melhores preditores para a compreensão leitora ou para os diferentes níveis de tratamento do texto nos resultados das várias análises de regressão realizadas. É provável que tais habilidades desempenhem um papel indireto no processo de compreensão de texto, relacionando-se estreitamente à habilidade de precisão de leitura e ao vocabulário.

As habilidades de consciência fonológica, por exemplo, parecem ser importantes preditores em se tratando do aprendizado inicial da leitura. Em função da escolaridade e do desenvolvimento, outras variáveis, tais como a habilidade para leitura de palavras e o vocabulário, passam a ter um papel mais importante como preditores da variabilidade encontrada no desempenho dos aprendizes (Goff, Pratt, \& Ong, 2005).

A consciência morfológica por sua vez, poderia contribuir de forma indireta para a leitura por meio do entendimento do desenvolvimento do vocabulário. O conhecimento da estrutura das palavras poderia ajudar o entendimento do significado de uma palavra.

De forma semelhante, a nomeação automatizada rápida e a memória de trabalho parecem ter também importância indireta quando se considera o desempenho geral dos jovens e adultos em tarefas de compreensão de textos escritos. Apesar das correlações significativas encontradas inicialmente, a nomeação automatizada rápida e a memória de trabalho não apareceram como melhores preditores de forma geral para a compreensão leitora. No entanto, diferentemente do modelo sugerido para as habilidades metalinguísticas, a nomeação automatizada rápida e a memória de trabalho tem uma contribuição específica quando relacionadas aos níveis de tratamento do texto. A nomeação automatizada rápida e a memória de trabalho têm uma contribuição específica quando são analisadas também as respostas dos jovens e adultos às perguntas relacionadas a detalhe e à inferência, o que será discutido a seguir.

\section{Correlatos Linguístico-Cognitivos dos Diversos Niveis de Compreensão Textual}

Os níveis de compreensão textual, segundo van Dijk e Kintsch (1983) são classificados em compreensão dos temas principais (macroestrutura), da argumentação e dos detalhes, além da realização de inferências. Tais níveis implicariam em diferenças no processamento do texto durante a leitura (Kintsch, 1988), e, possivelmente, diferenças em seus correlatos linguístico-cognitivos. Os resultados deste estudo descrevem, então, a relação entre determinadas habilidades linguístico-cognitivas e o desempenho de jovens e adultos tardiamente escolarizados em cada um dos diferentes níveis de tratamento do texto na leitura.

No que se refere à macroestrutura observou-se que dos correlatos linguístico-cognitivos deste nível de tratamento do texto, aqueles que melhor predizem o desempenho dos jovens e adultos são a precisão de leitura e o vocabulário. Tais correlatos são os mesmos que melhor descrevem também o desempenho dos jovens e adultos quanto à compreensão leitora de forma geral. Tais resultados revelam não uma coincidência, mas a importância da contribuição do entendimento dos temas relevantes (macroestruturas) para a reconstrução pelo leitor dos sentidos do texto escrito (compreensão leitora). Para um melhor desempenho na leitura o leitor precisará construir uma representação mental do texto escrito (Ramos, 2006). O leitor precisa ter acesso ao significado dos vocábulos, além de ter como parâmetro o contexto e o seu uso, podendo assim derivar a significação das ideias centrais daquilo que foi lido (Anderson, 1983).

Os itens de argumentação correlacionaram-se significativamente com todas as habilidades linguístico-cognitivas, com exceção da tarefa de julgamento de fonema inicial. Porém, o melhor preditor para o desempenho dos jovens e adultos em suas respostas aos itens de argumentação seria o vocabulário. Segundo van Dijk e Kintsch (1983) existe a possibilidade dos itens argumentativos exigirem do leitor a realização de um esforço de compreensão envolvendo outros processos além da seleção das ideias mais importantes. Tais esforços estariam relacionados às justificativas, explicações e fundamentos relacionados às ideias principais do texto. Nesse sentido, nossos resultados corroboram a estreita relação de que as estruturas argumentativas têm com o léxico mental dos leitores e através dele 
da experiência e conhecimentos destes leitores (Dockrell \& Lindsay, 2004; Kintsch, 1988). A compreensão textual implica, portanto, um processo complexo entre palavras e significados.

Os itens de detalhe correlacionaram-se significativamente com todas as habilidades linguístico-cognitivas, exceto com a tarefa de julgamento de fonema inicial. Porém os melhores preditores do desempenho dos jovens e adultos para itens dizem respeito à nomeação automatizada rápida (itens alfanuméricos) e a memória de trabalho. Neste sentido, a resposta aos itens de detalhe parece requerer sobremaneira as habilidades de processamento do leitor. Para responder perguntas referentes a detalhes, o leitor necessita de precisão de leitura para encontrar determinada informação no corpo do texto. Necessita simultaneamente manter na memória de trabalho o tipo de informação que precisa ser localizado no texto. Ao mesmo tempo necessita ter capacidade rápida de processamento para reconhecer a informação ao longo do texto, o que implica rapidez de acesso às correspondências grafofonêmicas que permitam o reconhecimento dos vocábulos. Tais operações mentais vão requerer a contribuição específica da memória e do processamento rápido das informações fonológicas (Helene \& Xavier, 2003; Misra et al., 2004).

No que se refere à inferência houve relação significativa com a memória de trabalho e com nomeação automatizada rápida, especificamente para a tarefa figurativa, sendo ambos bons preditores para os itens de inferência. A memória de trabalho, por sua vez, contribui de forma positiva para a compreensão textual já que por meio dela as novas informações, as informações já aprendidas e as lembranças arquivadas são recuperadas rapidamente e integradas (Helene \& Xavier, 2003). A memória de trabalho correlaciona-se com tarefas que requerem o processamento e a retenção de palavras (de Beni, Palladino, Pazzaglia, \& Cornoldi, 1998), sentenças (Seigneuric, Ehrlich, Oakhill, \& Yuill, 2000) e conhecimento factual (Bottino et al., 2010; Nation et al., 1999). Compreendedores menos habilidosos têm dificuldade no processamento semântico, o que restringe a sua habilidade para a estocagem de informação verbal na memória de trabalho (Nation et al., 1999).

Para a realização de inferências é necessário que o leitor acesse conhecimentos que foram construídos anteriormente (Bottino et al., 2010; Cain \& Oakhill, 2003). O conhecimento prévio é, portanto, bastante relevante tanto para a compreensão, quanto para a organização do conhecimento na memória. O conhecimento prévio é fundamental no momento em que o leitor entra em contanto com o texto, pois dá margem ao leitor para estabelecer a coerência do texto lido. Ainda para os autores, o conhecimento prévio é classificado em vários níveis, dentre eles encontra-se o linguístico, que inclui desde a pronúncia das palavras, até o conhecimento da língua, perpassando pelo conhecimento dos vocábulos. Nesse sentido, existe uma relação consistente entre a realização de inferência, as habilidades de processamento e o léxico mental.
De forma mais complexa do que o previsto pelo modelo simples de leitura (Goff et al., 2005), ler implica a integração por parte dos jovens e adultos de diferentes habilidades linguístico-cognitivas para a criação de significados. A importância da escolaridade para a compreensão textual de forma geral como para os diversos níveis de tratamento do texto que não sejam a busca por detalhes evidencia o lugar privilegiado destinado à escola para a construção do conhecimento.

Jovens e adultos escolarizados tardiamente deveriam ter tido a oportunidade de frequentar a escola na idade apropriada, e, consequentemente, ter podido adquirir os conhecimentos e as habilidades linguístico-cognitivas relacionadas à escolarização básica. Por outro lado, como resultado da maturidade e da experiência de vida, adultos escolarizados tardiamente estão em uma condição singular em relação aos aprendizes com trajetória escolar regular. Neste sentido, as investigações acerca de como tais jovens e adultos aprendem, representam, recordam e compreendem a informação podem concorrer para a oferta a estes aprendizes de oportunidades educacionais apropriadas.

\section{Referências}

Anderson, J. R. (1983). A spreading activation theory of memory. Journal of Verbal Learning and Verbal Behavior, 22, 261-295.

Bottino, A. G. (2004). A compreensão da linguagem escrita na educação de jovens e adultos (Dissertação de mestrado, Universidade Gama Filho, Rio de Janeiro, RJ, Brasil).

Bottino, A. G., Emmerick, T. A., \& Soares, A. B. (2010). Promovendo a compreensão de textos em estudantes. Educar em Revista, 38, 145-156.

Cain, K., \& Oakhill, J. V. (2003). The development of comprehension skills. In T. Nunes \& P. Bryant (Eds.), Handbook of children's literacy (pp. 155-180). Dordrecht, Netherlands: Kluwer Academic.

Capellini, S. A, Ferreira, T. L., Salgado, C. A., \& Ciasca, S. M. (2007). Desempenho de escolares bons leitores, com dislexia e com transtorno do déficit de atenção e hiperatividade em nomeação automática rápida. Revista da Sociedade Brasileira de Fonoaudiologia, 12(2), 114-119.

Cardoso-Martins, C., \& Michallick-Triginelli, M. F. (2009). Codificação fonológica e ortográfica na dislexia de desenvolvimento: Evidência de um estudo de caso. Arquivos Brasileiros de Psicologia, 61(1), 153-161.

Cardoso-Martins, C., \& Pennington, B. F. (2001). Qual é a contribuição da nomeação seriada rápida para a habilidade de leitura e escrita? Evidência de crianças e adolescentes com e sem dificuldades de leitura. Psicologia: Reflexão e Crítica, 14(2), 387-397.

Colomer, T., \& Camps, A. (2002). Ensinar a ler, ensinar a compreender. Porto Alegre, RS: Artmed.

Correa, J., \& Dockrell, J. E. (2007). Unconventional word segmentation in Brazilian children's early text production. Reading \& Writing, 20, 815-831.

Corrêa, M. F. (2009). Como os adultos aprendem a ler? Evidencias de um estudo com adultos pouco alfabetizados $e$ crianças com a mesma habilidade de leitura (Dissertação de mestrado, Universidade Federal de Minas Gerais, Belo Horizonte, MG, Brasil).

De Beni, R., Palladino, P., Pazzaglia, F., \& Cornoldi, C. (1998). 
Increases in intrusion errors and working memory déficit of poor comprehenders. The Quarterly Journal of Experimental Psychology: Human Experimental Psychology, 51A(2), 305-320.

Denckla, M. B., \& Rudel, R. (1974). Rapid automatized naming of pictured objects, colors, letters and numbers by normal children. Cortex, 10(2), 186-202.

Dockrell, J. E., \& Lindsay, G. (2004). Specific speech and language difficulties and literacy. In T. Nunes \& P Bryant (Eds.), Handbook of children's literacy (pp. 403-435). Dordrecht, Netherlands: Kluwer Academic.

Ferreira, T. L., Capellini, S. A., Ciasca, S. M., \& Tonelotto, J. M. F. (2003). Desempenho de escolares leitores proficientes no teste de nomeação automatizada rápida - RAN. Temas Desenvolvimento, 12(69), 26-32.

Galletly, S. A., Knight, B. A., Dekkers, J., \& Galletly, T. A. (2009). Indicators of late emerging reading-accuracy difficulties in Australian schools. Australian Journal of Teacher Education, 34(5), 54-64.

Goff, D. A., Pratt, C., \& Ong, B. (2005). The relations between children's reading comprehension, working memory, language skills and components of reading decoding in a normal sample. Reading and Writing, 18, 583-616.

Griva, E., \& Anastasiou, D. (2009). Morphological strategies training: The effectiveness and feasibility of morphological strategies training for students of English as a foreign language with and without spelling difficulties. Journal of Writing Research, 1(3), 199-223.

Helene, A. F., \& Xavier, G. F. (2003). Construção da atenção a partir da memória. Revista Brasileira de Psiquiatria, 25, $12-20$

Hoover, W. A., \& Gough, P. B. (1990). The simple view of reading. Reading and Writing, 2(2), 127-160.

Kintsch, W. (1988). The role of knowledge in discourse comprehension: A construction model. Psychological Review, 95(2), 163-182.

Kintsch, W. (1998). Comprehension: A paradigm for cognition. Cambridge, MA: Cambridge University Press.

Kintsch, W., \& van Dijk, T. A. (1978).Toward a model of text comprehension and production. Psychology Review, 85(5), 363-394.

Misra, M., Katzir, T., Wolf, M., \& Poldrack, R. (2004). Neural systems of rapid automatized naming in skilled readers: Unraveling the RAN - reading relationship. Scientific Studies of Reading, 8(3), 241-256.

Morais, A. G. (2005). O desenvolvimento de habilidades de reflexão fonológica em adultos e jovens pouco escolarizados: Seu papel no aprendizado do sistema de escrita alfabética. In T. F. Leal \& E. B. C. Albuquerque (Eds.), Desafios da educação de jovens e adultos: Construindo práticas de alfabetização (pp. 151-172). Belo Horizonte, MG: Autêntica.

Mota, M. M. E. P., \& Castro, N. R. (2007). Alfabetização e consciência metalinguística: Um estudo com adultos não alfabetizados. Estudos de Psicologia (Campinas), 24(2), 169-179.

Nascimento, E. do (2000). Adaptação e validação do teste WAIS-III para um contexto brasileiro (Tese de doutorado, Universidade de Brasília, DF, Brasil).

Nation, K., \& Snowling, M. (1998). Individual differences in contextual facilitation: Evidence from dyslexia and poor reading comprehension. Child Development, 69, 996-1011.

Nation, K., Adams, J. W., Bowyer-Crane, C. A., \& Snowling, M.
J. (1999). Working memory deficits in poor comprehenders reflect underlying language impairments. Journal of Experimental Child Psychology, 73(2), 139-158.

Perfetti, C. A., Marron, M. A., \& Foltz, P. W. (1996). Sources of comprehension failure: Theoretical perspective and case studies. In C. Cornoldi \& J. Oakhill (Eds.), Reading difficulties: Processes and intervention (pp. 137-165). Mahwah, NJ: Lawrence Erlbaum.

Ramos, W. M. (2006). A compreensão leitora e a ação docente na produção do texto para o ensino a distância. Linguagem \& Ensino, 9(1), 215-242.

Ribeiro, V. M. (1999). Alfabetismo e atitudes: Pesquisa com jovens e adultos. São Paulo, SP: Papirus.

Sánchez, E. (2002). Compreensão e redação de textos: Dificuldades e ajudas. Porto Alegre, RS: Artmed.

Seigneuric, A., Ehrlich, M.-F., Oakhill, J. V., \& Yuill, N. M. (2000). Working memory resources and children's reading comprehension. Reading and Writing, 13, 81-103.

Stanovich, K. E. (1993). A model for studies of reading disability. Developmental Review, 13, 225-245.

Stein, L. (1994). Teste de desempenho escolar. São Paulo, SP: Casa do Psicólogo.

van Dijk, T. A., \& Kintsch, W. (1983). Strategies of discourse comprehension. Nova York: Academic Press.

Vellutino, F. R., Fletcher, J. M., Snowling, M. J., \& Scanlon, D. M. (2004). Specific reading disability (Dyslexia): What have we learned in the past four decades? Journal of Child Psychology and Psychiatry, 45(1), 2-40.

Wagner, R. K., \& Torgesen, J. K. (1987). The nature of phonological processing and its causal role in the acquisition of reading skills. Psychological Bulletin, 101(2), 192-212.

Wilson, S. (2000). Single case experimental designs. In G. M. Breakwell, S. Hammond, \& C. Fife-Schaw (Eds.), Research methods in psychology (pp. 59-87). London: Sage.
Recebido: 21/07/2011

$1^{a}$ revisão: $26 / 03 / 2012$

$2^{a}$ revisão: 02/05/2012

Aceite final: 09/05/2012 